\title{
Comparative Study of 3G and 4GLTE Network
}

\author{
A. D. Abioye, M. K. Joseph, and H. C. Ferreira
}

\begin{abstract}
The area of mobile communication is fast developing as a result of the technological advancement in the field of mobile and wireless communication. Obviously, $3 \mathrm{G}$ was once acclaimed as a recent technology in the field of wireless and mobile communication until the arrival of 4GLTE. The quest for a faster speed, lower latency, better QoS and ability to interoperate with all existing network are some of the factors that brought up the emergence of 4GLTE network. In this paper we provide an overview of all network generations from the first generation to the fourth generation as well as the differentiating features that supports the superiority of the 4GLTE network to the 3G network are well stated. We use self-analytical tools like bar charts to compare the features of 4GLTE and 3G networks. The concluding part of this paper presents improvements needed in 4GLTE.
\end{abstract}

Index Terms-3G, 4GLTE, OFDMA, comparison of 3G and 4GLTE networks.

\section{INTRODUCTION}

According to Hodgkinson [1], the emergence of wireless communication never came on board recently but for many decades the improvements were done to make it more developed to meet the end users' needs, more importantly in the area of mobile communications. The development in mobile broadband use is vivid recently, such that Internet generation grows to having broadband access everywhere. This affirms the mobile broadband market share and forecast report given by The NPD Group that active mobile broadband devices will reach 34 million, a nearly 50 percent increase from 2013. In recent times, browsing of the Internet, sending and receiving of emails, sending and receiving of music and videos are done through the use of the $3 \mathrm{G}$ network. With 4GLTE, the user experience is better enhanced as the lower latency brings better experience in gaming and other graphics related software. LTE was initially planned by NTT DoCoMo of Japan in November, 2004 as the international standard [2]. Today different cellular and wireless firms want a major increase in capacity which has to be carried in coming years beyond fourth generation of wireless standards in Long Term Evolution (4GLTE) [3] or 3GPP Long Term Evolution [4].

According to Kumaravel [5], 4GLTE network brings better benefits in its performance and capacity to both the end users and service providers. Even the migration from 4GLTE to LTE-Advanced and device to device communication [6] was done to a certain extent in non-African countries. But African countries are still experiencing challenges even to use and implement the 4GLTE network. Some of the

Manuscript received November 18, 2014; revised May 20, 2015. This work was supported in part by University of Johannesburg.

The authors are with University of Johannesburg, South Africa (e-mail: daveydavoo@yahoo.com,meeraj@uj.ac.za, hcferreira@uj.ac.za). promised benefits of 4GLTE are: downlink peak rate of $100 \mathrm{mbps}$ and an uplink peak rate of $1 \mathrm{Gbps}$, a low latency of less than 20ms, and a speed of 200mbps. With these improvements over $3 \mathrm{G}$ network, 4GLTE is superior and can be regarded as the needed technology for present developing world.

The remainder of this paper is organized as follows: In Section II we discuss the objectives and in Section III, we provide a brief description of the network generations from $1 \mathrm{G}$ to 4GLTE. Section IV deals with the methodology used for our findings on why 4GLTE is superior over $3 \mathrm{G}$. In Section V we provide the data analysis and results of comparative features between $3 \mathrm{G}$ and 4GLTE with priority given to the benefits of 4GLTE over $3 \mathrm{G}$ network. Thereafter, formulation of data to affirm comparison between the two networks was also done in this phase of the paper. In Section VI we use self-analytical tools like bar charts to establish the described merits of 4GLTE network described in Section V of the paper. Finally, in Section VII we conclude the paper showing the challenges faced by 4GLTE network in recent time.

\section{OBJECTIVES}

The main objective of this paper is to compare $3 \mathrm{G}$ and 4GLTE networks. The other sub-objectives are:

1) To determine the superiority of the 4GLTE network over the widely used $3 \mathrm{G}$ network.

2) To compare some features in particular: interoperability, latency, scalability, design specification, convergence, networking, cost effectiveness and data transmission rate.

3) To illustrate and compare downlink, uplink speed and latency between $3 \mathrm{G}$ and $4 \mathrm{GLTE}$.

To explore the challenges faced by 4GLTE network and its merit over $3 \mathrm{G}$.

\section{OVERVIEW OF WIRELESS NETWORKS}

Considering the mobile telephony and wireless communication, its history can be categorized into different generations of networks. The first generation $1 \mathrm{G}$ according to [7] is an analogue, voice based network. It evolved in the 1980s with some standards which includes: AMPS, NMT, TDMA and TACS. Its evolution to $2 \mathrm{G}$ network was basically due to its slow speed.

The three primary benefits of $2 \mathrm{G}$ network over its predecessor is that - phone conversations were digitally encrypted; $2 \mathrm{G}$ systems were significantly more efficient on the spectrum allowing for far greater mobile phone penetration levels; and $2 \mathrm{G}$ introduced data services for mobile, starting with SMS text messages. This network is primarily designed to offer voice services to the subscriber 
hence it has a low transfer rates. It is primarily based on CDMA and TDMA, depending on the multiplexing technique used. The $2 \mathrm{G}$ is widely referred to as the GSM

The $2 \mathrm{G}$ and the $3 \mathrm{G}$ network have two network generation bridges between them. They are the $2.5 \mathrm{G}$ and $2.75 \mathrm{G}$. The $2.5 \mathrm{G}$ is a value added network to the preceding $2 \mathrm{G}$ network such that it adds packet switching technique to the existing circuit switching. It is widely referred to as GPRS such that the circuit switching controls the voice part of the network while packet switching controls the data transmission in the network. CDMA2000 came into existence through the introduction of the GPRS network. The major disadvantage of this network is that it has a low speed in practice (i.e. its theoretical speed is faster than the practical speed). The evolution from $2.5 \mathrm{G}$ to $2.75 \mathrm{G}$ occurred through the introduction of 8psk to the GPRS network. This leads to an enhance data transmission rate.

EDGE was standardized by 3GPP as part of the GSM family and it is an upgrade that provides a three-fold increase in capacity of GSM and GPRS networks. However, the second generation network system was found inadequate in global roaming, capacity and speed. These lacking features leads to the evolution of the third generation network system.

The primary aim for the emergence of the third generation network system is specifically to offer greater speed in practice to the subscribers and also support multimedia activities. According to [8], based on the initiative-2000, the International Telecommunication Union (ITU) defined $3 \mathrm{G}$ network as a wireless network that is capable of high speed in data transmission, ranging from $144 \mathrm{kbps}$ to greater than 2 mbps.

The main reason for $3 \mathrm{G}$ to $4 \mathrm{G}$ all IP network evolution is to form the same platform for all the pre-existing networks so as to meet users' needs as regards the expected improvement it offers. In addition to all the $3 \mathrm{G}$ facilities, data transmission is believed to go through the roof with speeds ranging between 100MBPs to 1GBPS - due to its fast speed, it is tagged a network of "connect anytime, anywhere, anyhow". 4G will provide very smooth global roaming.

TABLE I: SUMMARY OF NETWORK GENERATIONS (1G-4G) [9]

\begin{tabular}{|c|c|c|c|c|c|}
\hline Technology & $1 G$ & $2 G$ & $2.5 G$ & 3G & 4G \\
\hline Year & 1970 & 1980 & 1985 & 1990 & 2000 \\
\hline Standards & $\begin{array}{l}\text { AMPS, } \\
\text { NMT, ETACS,TACS }\end{array}$ & $\begin{array}{l}\text { GSM, } \\
\text { D-AMPS }\end{array}$ & EDGE, GPRS & $\begin{array}{l}\text { CDMA } \\
\text { 2000, WCDMA }\end{array}$ & $\begin{array}{l}\text { Single standard } \\
\text { LTE- } \\
\text { Advanced }\end{array}$ \\
\hline $\begin{array}{l}\text { Data band- } \\
\text { width }\end{array}$ & $1.9 \mathrm{Kbps}$ & $\begin{array}{l}14.4 \\
\text { Kbps }\end{array}$ & $384 \mathrm{Kbps}$ & $2 \mathrm{Mbps}$ & 200Mbps \\
\hline Core network & PSTN & PSTN & PSTN, Packet network & Packet network & Internet \\
\hline $\begin{array}{l}\text { Multipl- } \\
\text { exing }\end{array}$ & FDMA & CDMA, TDMA & CDMA, TDMA & $\begin{array}{l}\text { CDMA } \\
\text { 2000, WCDMA }\end{array}$ & OFDMA \\
\hline Service & Analog voice & Digital voice & Packet data and high capacity & $\begin{array}{l}\text { High capacity and broad- } \\
\text { band data }\end{array}$ & $\begin{array}{l}\text { Broad- } \\
\text { bandwith high speed }\end{array}$ \\
\hline
\end{tabular}

In Table I we compare the standards, data bandwidth, core network, multiplexing and services of IG to $4 \mathrm{G}$ networks. In $4 \mathrm{G}$ networks, we have the WIMAX and LTE networks and both are IP based.

\section{Methodology}

We use quantitative data obtained for some differentiating features of $3 \mathrm{G}$ and 4GLTE networks based on literature reviews. Quantitative measures and charts were utilized to generate information which established the superiority of 4GLTE over the $3 \mathrm{G}$ network. Using charts we illustrate and compare downlink, uplink speed and latency between $3 \mathrm{G}$ and 4GLTE. These data were from the South African providers. Moreover, based on literature review the advantages of 4GLTE network over 3G network was discussed in this paper In the next section we discuss features such as interoperability, latency, scalability, design specification, convergence, networking, cost effectiveness and data transmission rate.

\section{DATA ANALYSIS AND RESULTS}

In this section we discuss the merits of 4GLTE over $3 \mathrm{G}$ networks. Based on literature review, the following features show the advantage of 4GLTE network over $3 \mathrm{G}$ network. They are stated as follows:
Interoperability: This feature shows LTE as a network that has the ability to roam with other existing networks. It helps LTE to be a mobile and portable network such that the service providers are not limited to a single network system. Conversely, in $3 \mathrm{G}$ different standards makes it hard to interoperate and roam with other existing networks.

Latency: It simply means the delay of packet sent from a server to get the client and then back. In the LTE network, there's a very low latency which enhances speed of the network because they are interconnected with other. The lower the rate of latency or delay in response time, the faster the interaction between the device and the network to which it is connected [10]. Low latency in LTE is as a result of its support for games, application sharing, video and voice conferencing over IP.

Scalability: The ability to handle increasing numbers of users and diversity of services is referred to as scalability. It is a challenging process in $3 \mathrm{G}$ but done with ease in 4GLTE because it is an IP based network.

Design Specification: The 3G technology provides both circuit design and packet design such that the combination of these patterns makes $3 \mathrm{G}$ faster and better than the preceding network. 4GLTE which is regarded as a seamless network uses only packet switching which makes data transfer done in nanoseconds compared to $3 \mathrm{G}$ network [7].

Convergence: In contrast to $3 \mathrm{G}$, the fourth generation network based on research is said to be a conglomerate of all the existing network technologies rather than been a new 
standard alone. By analysis, 4G network is defined as combination of a local area network with the existing second generation network.

Networking: Unlike the third generation (3G) network which is specifically based on a wide-area concept whereby networking is limited, the 4GLTE network involves the hybrid networks which include both the wireless LAN and the base station WAN design [11]. For this reason, the end users have access to internet connectivity due to the presence of base stations everywhere.

Cost Effectiveness: 4GLTE is a cost effective network which doesn't require the purchase of an extra spectrum as it builds up on the existing networks. This is due to its capacity to interoperate with the existing networks. Therefore interoperability in LTE makes it a cost effective network compared to the $3 \mathrm{G}$ network.

Data Transmission Rate: the $3 \mathrm{G}$ network which is based on wideband CDMA operates in $5 \mathrm{MHz}$ of bandwidth and produces minimum download data rates of $384 \mathrm{~kb} / \mathrm{s}$ under normal conditions and close to $2 \mathrm{Mb} / \mathrm{s}$ as maximum rate. $3 \mathrm{G}$ phone standards was expanded and enhanced to further expand data speed and capacity. The WCDMA phones adds high speed packet access (HSPA) of higher level QAM modulation to get speeds up to 21 or $42 \mathrm{Mbps}$ downlink (cell site to phone) and up to 7 and/or 14 Mbps uplink (phone to cell site). While in the fourth generation network, a completely contrasting radio technology is used. LTE support both FDD (Frequency Division Duplexing) and TDD (Time Division Duplexing) and works with two multiplexing techniques namely OFDMA and SC-FDMA for uplink and downlink respectively [12].

Unlike CDMA in 3G, Orthogonal Frequency Division Multiplexing (OFDM) and OFDM access are used. Here, the modulation technique divides a channel usually 5,10 or 20 $\mathrm{MHz}$ wide into smaller sub-channels or subcarriers each 15 $\mathrm{kHz}$ wide. Each is modulated with part of the data. The fast data is divided into slower streams that modulate the subcarriers with one of several modulation schemes like QPSK or 16QAM.

TABLE II: COMPARISON OF 3G AND 4G NETWORKS [9]

\begin{tabular}{|c|c|c|}
\hline & $3 \mathrm{G}$ & $4 \mathrm{G}$ \\
\hline $\begin{array}{l}\text { Major } \\
\text { requirement } \\
\text { driving } \\
\text { architecture }\end{array}$ & $\begin{array}{l}\text { Predominantly voice } \\
\text { driven data was } \\
\text { always add on }\end{array}$ & $\begin{array}{l}\text { Converged data and } \\
\text { voice over IP }\end{array}$ \\
\hline $\begin{array}{l}\text { Network } \\
\text { architecture }\end{array}$ & Wide area cell based & $\begin{array}{l}\text { Hybrid-integration } \\
\text { of wireless LAN } \\
\text { and wide area }\end{array}$ \\
\hline Speed & 384Mbps-2Mbps & $\begin{array}{l}\text { 2Mbps-200Mbps } \\
\text { (in mobile mode) }\end{array}$ \\
\hline Frequency band & $\begin{array}{l}1800 \mathrm{MHz}- \\
2400 \mathrm{MHz}\end{array}$ & $2 \mathrm{GHz}-8 \mathrm{GHz}$ \\
\hline $\begin{array}{l}\text { Switching } \\
\text { technique }\end{array}$ & $\begin{array}{l}\text { Circuit and packet } \\
\text { switching }\end{array}$ & Packet switching \\
\hline $\begin{array}{l}\text { Access } \\
\text { technologies }\end{array}$ & W-CDMA & OFDM,MC-CDMA \\
\hline $\begin{array}{l}\text { Internet } \\
\text { Protocol }\end{array}$ & $\begin{array}{l}\text { A number of air link } \\
\text { protocol including } \\
\text { IP5.0 }\end{array}$ & All IP based(IPv6) \\
\hline
\end{tabular}

In Table II we compare the network architecture, speed, frequency band, switching techniques, access technologies and Internet protocols of $3 \mathrm{G}$ and $4 \mathrm{G}$ networks.
LTE, in its basic form, does not support uplink Multiple Input Multiple Output (MIMO) [12]. LTE MIMO technique that refers to utilize of multiple antennas at transmitter and receiver area may be applied for both DL as well as for UL channel [2]. LTE's ability to improve spectral efficiency much beyond the current LTE performances is very much unlikely, and so the only way to achieve that higher data rates is to increase the channel bandwidth [12].

\section{FINDINGS AND DISCUSSIONS}

This section of the paper shows the use of self-analytical tools to affirm the described differences and superiority of 4GLTE over the $3 \mathrm{G}$ network. The data used were gotten from South African Latency and Speed test result through the speed tester server for both $3 \mathrm{G}$ and 4GLTE network based on MTN South Africa network.

In Table III we compare the latency time and speed test results of $3 \mathrm{G}$ and $4 \mathrm{GLTE}$.

TABLE III: LATENCY AND SPEED TEST RESULT FOR MTN SA 3G AND

TABLE III: LATENCY AND SPEED TEST RESULT FOR MTN SA 3G AND
\begin{tabular}{|c|c|c|}
\hline & 4GLTE & 4GLTE \\
\hline Network Features & 3G & $44 \mathrm{~ms}$ \\
\hline Latency time & $91 \mathrm{~ms}$ & $7.74 \mathrm{Mbps}$ \\
\hline Uplink rate & $2.11 \mathrm{Mbps}$ & $23.92 \mathrm{Mbps}$ \\
\hline Downlink rate & $17.68 \mathrm{Mbps}$ & \\
\hline
\end{tabular}

In Fig. 1 we illustrate the chart representation for the downlink and uplink speeds in both $3 \mathrm{G}$ and 4GLTE networks, it can be confirmed that the downlink speed i.e. the speed from the base station to end users is higher in the 4GLTE network compared to that in the $3 \mathrm{G}$ network.

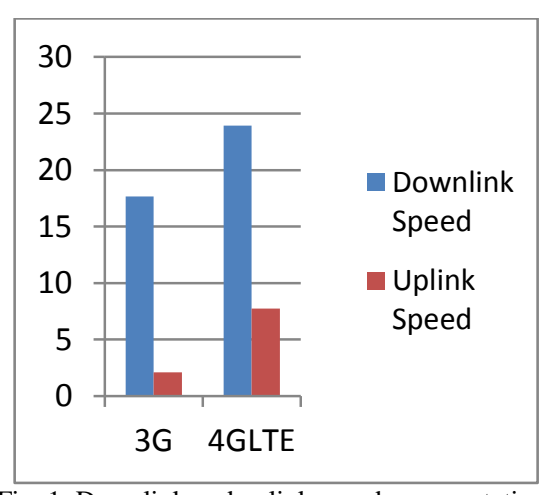

Fig. 1. Downlink and uplink speed representation.

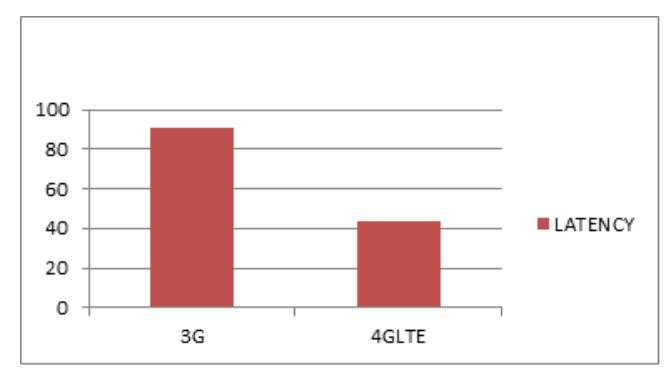

Fig. 2. Latency/delay time representation.

The above stated data shows the uplink data in 4GLTE is better off than $3 \mathrm{G}$ by a difference of $5.63 \mathrm{Mbps}$ in practice based on MTN SA [13] network.

By taking into account the cognizance of the uplink speed i.e. the speed for data upload is higher in 4GLTE network as compared to that of the $3 \mathrm{G}$ network by a difference of 
6.24Mbps as regards MTN SA [13] network. These speeds constitute to the greater data transfer rates found in 4GLTE network compared to that of $3 \mathrm{G}$ network.

Fig. 2 shows how delay time/latency that makes 4GLTE a superior network compared to the $3 \mathrm{G}$ network. Latency as known is the time taken for packet sent from the server to get to the end user and then back to the server. Comparing a latency of 44ms in MTN SA 4GLTE to the 99ms delay time found in MTN SA [13] 3G network, it simply means it takes a decreased delay time of $55 \mathrm{~ms}$ for packet sent on 4GLTE to get to the client and then back to MTN SA [13] 4GLTE server. This is a practical feature that makes 4GLTE network supports teleconferencing, games better than the $3 \mathrm{G}$ network.

\section{CONCLUSION AND Future RESEARCH}

In this paper we provide a high level overview from $1 \mathrm{G}$ to 4GLTE network and some factors responsible for migration from each network to another. We discuss the advantages of 4GLTE network over 3G network. The speed, in particular, the downlink and uplink, latency and the data transmission rates were analyzed to show the superiority of 4GLTE to $3 \mathrm{G}$ networks. Based on these proved features, 4GLTE network offers a highly competitive performance and it provides a good platform for further evolution. The downlink speed in 4GLTE is higher than $3 \mathrm{G}$, and the uplink data in 4GLTE is better off in 4GLTE and these networks also have a greater data transfer rates than $3 \mathrm{G}$ networks.

Nevertheless, 4GLTE requires improvement in interference cancellation at user terminal and as well, more research work is required in the area of VoIP in 4GLTE network. Migration from 4GLTE to LTE-Advanced and comparison of their performance aspects is also a challenge that needs critical consideration in the African context in particular. There is scope for future research on the use of 4GLTE for the end users.

\section{REFERENCES}

[1] T. G. Hodgkinson, "Wireless communication-the fundamentals," BT Technology Journal, vol. 25, no. 2, p. 1, 2007.

[2] S. S. Sengar, A. Singh, and P. N. Tripathi, "A survey on telecommunication technology standards," International Journal on Computer Science and Engineering, vol. 3, no. 5, pp. 2061-2067, 2011.

[3] R. R. Choudary, "A network overview of massive MIMO for 5G wireless cellular: System model and potentials," International Journal of Engineering Research and General Science, vol. 2, issue 4, June-July, pp. 338-347, 2014.

[4] Y. Tsai, G. Zhang, D. Grieco, and F. Ozluturk, "Cell search in 3GPP long term evolution systems," IEEE Vehicular Technology Magazine, vol. 2, no. 2, pp. 23-29, 2007.

[5] K. Kumaravel, "Comparative study of $3 \mathrm{G}$ and $4 \mathrm{G}$ in mobile technology," International Journal of Computer Science Issues, vol. 8, issue 5, pp. 256-259, 2011.

[6] K. Doppler, M. Rinne, C. Wijting, C. B. Ribeiro, and K. Hugl, "Device-to-device communication as an underlay to LTE-advanced networks," IEEE Communications Magazine, vol. 47, issue 12, pp, 42-49, 2009.

[7] R. Datta and Niharika, "Comparison study between the generations of mobile communication 2G, 3G and 4G," International Journal On Recent and Innovation Trends In Computing and Communication, vol. 1, issue 4, pp. 329-330, 2013.

[8] A. R. Mishra, Advanced Cellular Network Planning and Optimization, 1st ed. England: John Wiley, 2012, pp. 9-10.

[9] O. O. Fagbohun, "Comparative studies on 3G, 4G and 5G wireless technology," International Journal of Electronics and Communication Engineering (IOSR-JECE), vol. 9, issue 3, pp. 2-4, 2014.

[10] A. Kumar et al., "Comparison of $3 \mathrm{G}$ wireless networks and $4 \mathrm{G}$ wireless networks," International Journal of Electronics and Communication Engineering, vol. 6, no. 1, pp. 3-4, 2013.

[11] G. Joythi, P. Nagakalyan, and B. Jabber, "4G-Mobile technology: An adaptive approach to wireless networks," International Journal of Computer Technology and Electronics Engineering, vol. 2, issue 6, pp. 57-59, 2012.

[12] A. Oudah, T. A. Rahman, and N. H. Seman, "Taking the journey from LTE to LTE-Advanced," International Journal of Advances in Engineering \& Technology, pp. 26-33, Sep. 2011.

[13] MTN SA. (2014). [Online]. Available: www.mtn.co.za

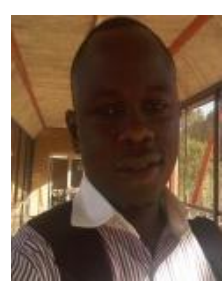

A. D. Abioye completed his B.Tech. degree in Nigeria and is pursuing his M.Tech. degree of electrical engineering at University of Johannesburg, South Africa. His research interests include 4G, 4GLTE networks and telecommunications.

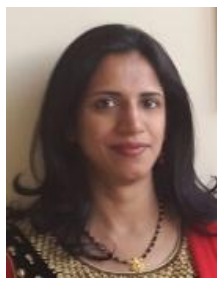

Meera K. Joseph received the degree of DPhil. in engineering management from University of Johannesburg in 2013 and M.C.A degree in 1997 from Bangalore University, India. Many post graduate students completed under her supervision and she has many IEEE international conference papers, journal papers and book chapters to her credit. Her research interests include information and communication technology for development, smart grids, cloud computing, networks and telecommunications. She works as a senior lecturer at UJ and is a professional member of IITPSA.

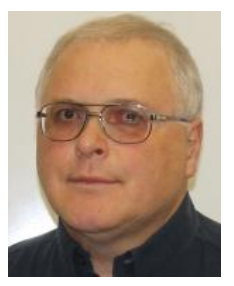

H. C. Ferreira received the degrees of B.Sc. (Eng.) in electrical (cum laude) in 1976, M.Sc. (Eng.) in electronic (cum laude) in 1978, and D.Sc. (Eng.) in 1980 from the University of Pretoria. From 1980 to 1981, he was invited to be a post-doctoral researcher at the Linkabit Corporation (Predecessor of Qualcomm) in San Diego, CA, USA. In 1983, he joined the Rand Afrikaans University, Johannesburg, South Africa (currently University of Johannesburg) where he was promoted to professor in 1989 . He has served several terms chairing staff and line functions within the RAU Faculty of Engineering's unique pre-1994 matrix structure, and also two terms as a chairman of the Department of Electrical and Electronic Engineering, from 1994 to 1999. Since 1984, he has been a visiting researcher at seven universities and two companies in both the USA and Europe. This includes the Institute for Experimental Mathematics at the University of Duisburg-Essen in Germany, with whom his research group has had a cooperation and exchange agreement since 1992. His research interests are in digital communications and information theory, especially coding techniques. His current applications of the research include power line communications, video communications and networks. 